\title{
TRADUÇÃO DO TRATADO SOBRE A ESFERA DE J.-J. ROUSSEAU
}

Tradução, apresentação e notas de Marcos Saiande Casado e Manoel Jarbas Vasconcelos Carvalho

Revisão da tradução: Marcos Antônio de Carvalho Lopes

\section{Apresentação}

Trata-se da tradução do Traité de sphère, escrito por Jean-Jacques Rousseau, provavelmente no período que compreende os anos de 1735 a 1738. O Tratado sobre a Esfera compõe o conjunto das chamadas obras científicas produzidas por Rousseau na edição de Euvres complètes de Jean-Jacques Rousseau, Édition thématique du Tricentenaire, Slatkine/Honoré Champion (2012). A referida edição conta com um importante estudo introdutório sobre os trabalhos científicos de Rousseau redigidas por Christophe Van Staen.

A falta de precisão no que diz respeito ao ano de produção do texto se dá pelo desaparecimento do manuscrito original. O acesso ao texto se deu, segundo Christophe Van Staen (2012, p. 4), por intermédio de Streckeisen-Moultou, a quem se deve a primeira edição do manuscrito. O responsável por esta edição se limitou a afirmar que segundo "uma tradição familiar", esse era "o trabalho de uma manhã", composto "para a senhora de seus amigos" e “cujo nome não foi preservado". Van Staen se apoia na tese de M. Launay, que optou por situar o Tratado ao mesmo tempo que o Cours de géographie e a Réponse au mémoire anonyme intitulé, ou seja, entre 1735 e 1738. Uma outra data, posterior a 1760, também é tomada por alguns especialistas como sendo a data mais provável na escrita do Tratado. É o caso da edição dos textos de Rousseau feita por Christopher Kelly (2007, p. 298). Nessa edição, o tradutor aponta a data de 1767, haja vista o fato de que Rousseau viveu na casa do Príncipe de Conti, em Trye, de junho de 1767 até junho de 1768, lugar no qual Rousseau faz referência no decorrer do Tratado. Mas esse argumento não parece muito confiável para Van Staen. Um simples erro do copista pode ter trocado "Troyes" (uma cidade muitas vezes retida como um ponto de comparação no plano astronômico e tabelas geográficas da época) por "Trye", ou mesmo o fato de Rousseau ter citado Trye simplesmente por acaso, são contra-argumentos que enfraquecem as hipóteses que situam o texto para além do ano de 1738. Contudo, a proximidade de conteúdo que se verifica entre o Cours de géographie e o Tratado sobre a Esfera é o fato que determina para M. Launay - e assumida por Van Staen -, o período de 1735 a 1738, como sendo a data mais certa da produção desse texto. 
Acreditamos que a tradução para a nossa língua do Tratado sobre a Esfera representa um importante esforço para ressignificar os sentidos e os significados que a leitura das grandes obras de Rousseau provocou e provoca no leitor de língua portuguesa que não teve acesso a esse trabalho no idioma original do seu autor. Junto à tradução de $O$ novo labirinto (2020), O Tratado sobre a Esfera visa, ainda, contribuir para trazer ao público de língua portuguesa, um Rousseau preocupado com o aquilo que hoje chamamos por ciências da natureza e que por muito tempo passou desapercebido quando da leitura do Rousseau Educador, do Rousseau Político ou do Rousseau Moralista. Como afirma Christophe Van Staen, “Apesar de seu caráter elementar e até desajeitado, e contra o a priori comum que faz de Rousseau um desdenhoso irrefletido e mal documentado da ciência, esses pequenos textos escritos entre 1735 e 1738 têm importância.” (2012, p. 3).

\section{Tratado sobre a esfera de J.J. Rousseau}

\section{[Primeiro capítulo]}

Para saber agir aprendamos a pensar. Saber pensar é o talento mais universal da vida humana. É unicamente por meio dele que se pode tirar proveito para si da fortuna, dos outros, e de si próprio. Todas as coisas sendo iguais, quem pensar melhor está mais próximo da felicidade. Pensar é ter ideias e combiná-las; é ver objetos e compará-los; é encontrar as verdadeiras relações que existem entre eles; é obter resultados que conduzam ao conhecimento da verdade; é ordená-los (adaptá-los) às coisas que nos são úteis. Portanto, a arte de pensar é a arte de nos tornar felizes, na medida em que depende de nós. Logo, depende de nós muito mais do que se pensa; e a maioria dos homens está menos infeliz com sua própria situação, porque não sabe como tirar proveito dela.

Aprender a pensar, portanto, é o nosso primeiro destino nesta vida; é aprender a nos tornar felizes. Mas esse conhecimento requer muitos outros. Não geramos nossas próprias ideias, elas nos vêm de fora.

Para conseguir se conhecer a si mesmo, é preciso conhecer muitas coisas que não são nós mesmos. Um homem só (apenas) se conhece bem quando conhece bem os outros homens; e para conhecer os homens, é preciso também conhecer as coisas das quais eles dependem. Então tudo se encaixa. A sabedoria leva à felicidade, o conhecimento leva à sabedoria. A melhor 
mente natural não é nada sem a educação ${ }^{1}$. Com os melhores olhos, o homem mais previdente não veria nada se não tivesse aprendido a ver desde a infância.

Para aprender a nos conhecermos, comecemos a estudar o que nos rodeia. Para se conhecer, você tem que conhecer o homem. Para conhecer o homem, é preciso estudar os homens; e para conhecer os homens é preciso estudá-los em diversos tempos, em diversos lugares $^{2}$. É preciso começar vendo-os no quadro geral da História. É aí que, ao contemplá-los em todas as situações possíveis, entregues a todas as paixões humanas, a todas as vicissitudes das coisas, expostos a todos os jogos da fortuna, ora malucos ora sábios, ora bons e ora maus, nesta prodigiosa variedade de relações e diferenças, aprenderemos a desenredar o que é essencial ao homem, o que dele é inseparável, o que aí sempre encontramos, do que é apenas acidental, e o que pode mudar nele segundo as nações e segundo os séculos. Nos contrastes, de virtudes e crimes, de fraqueza e força, de grandeza e pequenez, que muitas vezes nos surpreenderão, aprenderemos a libertar o homem de sua máscara, e a não acreditar que conhecemos a natureza humana o suficiente vendo os homens que estão ao nosso redor.

\section{Segundo capítulo}

Antes de procurar a origem da humanidade, vamos dar uma olhada em sua morada; ela é digna de algumas observações. A morada do homem e de todos os animais, esta terra coberta com tantas árvores e plantas, tantas montanhas e vales, tantas rochas e mares; este vasto mundo sem limite e sem fim, é aos nossos olhos materiais uma morada muito grande, mas muito pequena aos olhos da nossa razão, quando eles [os olhos] começam a se abrir. No imenso espaço exterior, nesta espantosa vastidão onde se afoga a imaginação, transporto-me pelo pensamento numa destas enormes e luminosas massas, que rolam majestosamente sobre as nossas cabeças; e vejo de longe um grão de areia, flutuando neste mar aéreo. Ele escapa da minha vista por sua pequenez, preciso de óculos para vê-lo. Eu pergunto, rindo, se há ácaros suficientemente pequenos o para habitar esse grão de areia? Sem dúvida, disse-me um filósofo local, está coberto de não sei quais pequenos insetos que se chamam homens e que dividiram sua superfície em regiões, nações, províncias. Eles construíram lá cidades e vilas. Eles fundaram lá

\footnotetext{
${ }^{1}$ Nota-se aqui a preocupação de Rousseau em apontar a educação como o mecanismo adequado para desenvolver as potencialidades do homem.

${ }^{2}$ Rousseau jamais abandonará a ideia do homem como centro de seu pensamento. Mais tarde, no Discurso sobre a desigualdade, ele afirmará que "O mais útil e o menos avançado de todos os conhecimentos humanos pareceme ser o do homem" (1973d, p. 233).

\begin{tabular}{|c|c|c|c|c|}
\hline Govista Dialectus & Ano 10 & n. 23 & Maio - Agosto 2021 & p. $419-432$ \\
\hline
\end{tabular}
}


impérios e repúblicas. Eles lá estabeleceram reis, magistrados, os grandes (os poderosos). Eles montaram lá tribunais. Eles formaram lá academias, universidades, onde se debate seriamente se nós que estamos aqui somos alguma coisa ou nada. - Eis, retomo, répteis arrogantes e vaidosos, cuja prole eu esmagaria com grande prazer sob a unha. - Lentamente, retoma o filósofo saturnino; não vamos esmagar ninguém, para que não sejamos esmagados sob as unhas dos habitantes desses outros astros, maiores que o nosso sem comparação. Esses pobres animaizinhos com seus cinco pés de altura têm também boas razões para se acharem altos, como nós, com nossos vinte e cinco ou trinta pés, desses outros seres que talvez tenham setecentos ou oitocentos pés, que talvez não vejam nenhuma diferença na pequenez de uns e de outros, e que, talvez ainda, são também, eles próprios, tão pequenos aos olhos dos habitantes de Boötes e Sirius ${ }^{3}$. Somos, continua meu filósofo, e os habitantes da terra são como nós, muito grandes em alguns aspectos, muito pequenos em outros. Não há, portanto, grandeza absoluta. Não nos orgulhemos ou nos humilhemos com o que não é. Para todo ser finito, nada é grande ou pequeno, exceto por comparação.

Este mundo é, portanto, grande, não em si mesmo, mas para nós, que somos pequenos; é muito grande para a nossa estatura, para os nossos passos, para a medida dos nossos olhos. Não seria grande para os ogros que têm botas de sete léguas com as quais dariam a volta em um dia, e seria pequeno para os deuses de Homero que cruzam o espaço dos céus em três passos, e chegam ao quarto.

\section{Terceiro capítulo}

Há poucos séculos que se conhece a medida da terra, e a sua imagem. Até Cristóvão Colombo, que descobriu a América, conhecíamos apenas um lado do globo, ou seja, aquele em que habitamos. Entre os antigos, o vulgar acreditava que a terra era plana e que o sol se punha no mar; sem se preocupar muito com o que acontecia com este astro durante a noite, nem como, se pondo de um lado, ele nascia do outro. As pessoas mais esclarecidas possuíam apenas um conhecimento parcial. Eles na verdade, concebiam que o sol girava em torno da Terra e que a noite para o nosso hemisfério era o dia para o hemisfério oposto. Mas eles não tinham, no entanto, chegado a imaginar que a Terra fosse povoada por toda parte e que houvesse antípodas para nós; ou seja, pessoas no hemisfério oposto, que tivessem os pés contra os nossos, para

\footnotetext{
${ }^{3}$ Boötes e Sirius são, respectivamente, a constelação do Pastor ou do Boieiro e da estrela mais brilhante da constelação do Cão Maior.

\begin{tabular}{|l|l|l|l|l|}
\hline Revista Dialectus & Ano 10 & n. 23 & Maio - Agosto 2021 & p. $419-432$ \\
\hline
\end{tabular}
}


quem o sol nascesse quando se põe para nós e se pusesse quando nasce. O primeiro que ousou promover esta verdade foi excomungado por um papa. Hoje, os franceses, os ingleses, os holandeses têm colônias nas antípodas e seus navios vão lá e voltam de lá todos os dias. Portanto, é um fato muito certo que o globo terrestre é redondo ou quase redondo, e que há habitantes por toda parte que o sol ilumina sucessivamente enquanto gira em torno dela em vinte e quatro horas de leste a oeste. Eu digo que o sol gira em torno da Terra, para usar a expressão vulgar e para me acomodar às aparências. Pois é reconhecido que o sol está fixo, que é o globo da terrestre, que, girando sobre si mesmo em vinte e quatro horas, apresenta sucessivamente todos os pontos de seu círculo ao sol (o que torna um dia normal), e que, além disso, fazendo um grande círculo ao redor do sol a cada trezentos e sessenta e cinco dias, marca em seu retorno ao mesmo ponto o término de um ano. Mas, para não entrar em longas explicações, que exigiriam esferas e figuras, limitemo-nos ao suposto movimento do sol, pelo qual a desigualdade de dias e estações se explica de maneira mais fácil e menos confusa.

\section{Quarto capítulo}

Os traços circulares da marcha diurna do Sol, dividindo o mundo em duas partes iguais, são chamados de equador, ou linha equinocial, ou simplesmente a linha. Os dois pontos aparentes do globo que em ambos os lados formam o centro dessa linha são chamados de polos. Se o mundo girasse na mesma direção em um pivô, as duas extremidades desse pivô seriam os dois polos, e esse pivô seria chamado de eixo da Terra. É fácil imaginar daí que os países onde a linha passa e que estão perpendicularmente sob o curso do sol são países muito quentes, e que aqueles, pelo contrário, que estão longe deste curso sob os polos e nas proximidades são países muito frios. Aqueles que são intermediários entre a linha e um dos polos são países temperados, como é a França. O polo do nosso lado é chamado de polo ártico ou boreal; o que está do outro lado da linha é chamado de Antártico ou Polo Meridional. Esta é a razão simples e grosseira da desigualdade de climas. A da desigualdade de estações e dias é um pouco mais difícil de explicar sem uma imagem. Vamos tentar.

\section{Quinto capítulo}

O sol não faz seu círculo diário na linha todos os dias; pelo contrário, ele apenas a percorre exatamente dois dias no ano com seis meses de intervalo, e aqueles dois dias em que

\begin{tabular}{|c|l|l|l|l|}
\hline Q & Ano 10 & n. 23 & Maio - Agosto 2021 & p. 419-432 \\
\hline
\end{tabular}


o dia e a noite têm exatamente a mesma duração, são chamados de equinócios. No dia seguinte ao equinócio da primavera, o sol não percorre mais seu círculo diário na linha, mas ao lado da linha aproximando-se de nosso polo e, portanto, de nós; e continua a se aproximar dele todos os dias durante seis meses, até atingir um círculo chamado trópico; depois disso, em vez de se aproximar de nós novamente, ele se afasta dele se aproximando da linha; e a ultrapassando mesmo após o equinócio de outono, para ir até o outro trópico; aproximando-se do polo oposto e, portanto, se afastando de nosso e de nós. O dia em que o sol atingiu nosso trópico é nosso solstício de verão, e o solstício de inverno para aqueles que se encontram do outro lado da linha; inversamente, nosso solstício de inverno é o solstício de verão deles. Pode-se entender como a distância e a proximidade do sol tornam as estações frias ou quentes. Também é compreensível porque temos sombra ao meio-dia, mesmo no verão, o sol nunca estando completamente acima de nós. Só há aqueles que se encontram entre os trópicos, na zona dita tórrida ou ardente, que tendo o sol diretamente sobre a sua cabeça duas vezes por ano não tem sombra ao meio-dia nesses dois dias.

\section{Sexto capítulo}

Pelo que acabei de dizer, deve-se conceber que o sol gira diariamente de leste ao oeste na linha, ou em círculos paralelos à linha, em ambos os lados até o trópico. Seu curso anual é marcado de oeste para leste em um círculo oblíquo à linha equinocial que ele cruza em dois pontos, e em mais dois desses mesmos pontos este mesmo círculo toca os trópicos. Este círculo anual é chamado de eclíptica, porque é quando a Terra ou a Lua se encontra nesta linha com o Sol que ocorrem os eclipses. A faixa do céu no meio da qual é a eclíptica, e onde estão marcadas as doze constelações, pelas quais o sol passa anualmente, é chamada de Zodíaco.

Agora, passemos para a desigualdade dos dias e das noites.

\section{Sétimo capítulo}

Se, sob meus pés, colocássemos uma das pontas de um grande compasso, e que com a outra ponta um grande círculo fosse traçado ao meu redor, que dividisse o mundo em dois hemisférios ou meios-globos, um dos quais está parcialmente sujeito a minha visão em minha volta, e da qual a outra parte, que é oposta a ela, abaixo de mim, esteja oculta de minha vista; este círculo assim desenhado seria chamado de meu horizonte e, embora não estando realmente

\begin{tabular}{|c|l|l|l|l|}
\hline Q & Ano 10 & n. 23 & Maio - Agosto 2021 & p. 419-432 \\
\hline
\end{tabular}


desenhado, suponho, e tomo por este horizonte aproximadamente, a extensão que meus olhos podem descobrir dele ao meu redor. Cada homem tem, portanto, seu círculo particular ou horizonte, do qual é o centro. Mas, para nos limitarmos ao que é sensível, não tomamos as coisas estritamente dessa maneira, e como a um círculo tão grande podemos dar um grande centro, supomos o mesmo horizonte para um país inteiro. Porque, por exemplo, Trye ou Paris, podem. sem erro apreciável, serem tomadas como o mesmo centro, quando se trata de um círculo de nove mil léguas ao redor.

Nosso horizonte, portanto, divide o mundo em duas metades, uma das quais está sujeita à nossa visão e a outra que lhe está oculta. Enquanto o sol em sua marcha diurna estiver acima de nosso horizonte, é dia para nós, quando está abaixo, é noite, e no momento em que atinge o horizonte é o momento do amanhecer ou do entardecer. A marcha diurna do sol é um círculo. O horizonte é um outro círculo que cruza o primeiro; e é a maneira como esses dois círculos se cruzam que torna os dias grandes ou pequenos, as noites curtas ou longas, e uns e outros iguais ou desiguais.

Podemos apenas ver essas várias interseções de círculos em uma esfera. Mas aqui está o resultado dessa inspeção.

Os povos que estão abaixo do equador têm dias iguais entre si e as noites possuem a mesma duração ao longo do ano e, consequentemente, sempre o mesmo período, doze horas. Por que isso? Porque nesse clima, durante todo o ano, o horizonte corta o círculo diário do sol em duas partes iguais; daí segue-se que o sol, que descreve este círculo, permanece tanto tempo acima do horizonte quanto abaixo.

Sob os dois polos, ao contrário, há em todo o ano apenas um longo dia de seis meses e uma longa noite de seis meses. Por que isso? Porque nesta posição o equador ou o horizonte se confundem no mesmo círculo, e, consequentemente, durante os seis meses em que o sol está deste lado do equador, é dia sob o nosso polo e noite sob o polo oposto, e que durante os seis meses em que o sol está além do equador, é exatamente o oposto. Aqueles que vivem entre a linha e o polo têm dias longos e noites curtas no verão, noites longas e dias curtos no inverno; porque seu horizonte corta obliquamente e desigualmente o círculo diário do sol. Para entender como isso é feito, basta apenas colocar o globo de acordo com nossa posição. Então descobriremos que dos trezentos e sessenta e cinco círculos diários, aqueles que estão além do equador são cortados por nosso horizonte de modo que a porção de cada um desses círculos que está no horizonte é menor que a porção que está abaixo. Daí decorre que o sol, descrevendo os

\begin{tabular}{|l|l|l|l|l|}
\hline Qevista Dialectus & Ano 10 & n. 23 & Maio - Agosto 2021 & p. $419-432$ \\
\hline
\end{tabular}


ditos círculos no inverno, permanece abaixo do nosso horizonte por mais tempo do que acima e, portanto, a noite dura mais que o dia.

Ao contrário, os círculos diários ou paralelos que estão além do equador, são cortados pelo horizonte de tal modo que a parte maior do círculo fica acima e a menor abaixo; daí decorre que quando o sol descreve esses círculos, ou seja, no verão, os dias são mais longos que as noites. Mas quando o sol descreve o próprio círculo do equador, ou seja, nos dois equinócios, o dia é igual à noite e de doze horas, porque o equador é sempre cortado pelo horizonte em dois semicírculos iguais, e que, consequentemente, o sol leva tanto tempo para descrever um quanto o outro.

\section{Oitavo capítulo}

Depois de falar sobre a desigualdade das estações e dos dias, vamos dizer algumas palavras sobre o que é chamado de latitude, longitude e altura do polo.

Qualquer círculo, grande ou pequeno, é concebido como uma divisão em trezentas e sessenta partes iguais ou pequenos arcos, que são chamados de graus.

Um círculo que passa perpendicularmente ao equador através dos dois polos, é chamado de meridiano, ou melhor, suas duas metades de um polo ao outro, são dois meridianos, porque ao mesmo tempo que o sol passa por um ponto deste semicírculo, é meio-dia em todos os outros pontos e meia-noite em todos os pontos do semicírculo oposto.

Podemos fazer esses círculos passarem por todos os pontos do equador, e se concebermos pelo menos um em cada grau, haverá tantos meridianos quantos graus no equador, ou seja, trezentos e sessenta.

Da mesma forma, suponha um círculo meridiano dividido em trezentos e sessenta graus por outros tantos círculos paralelos ao equador; será de cento e oitenta graus para cada semicírculo ou meridiano, ou seja, noventa graus do equador ao polo de cada lado.

Dissemos que todos os semicírculos que passam por todos os graus do equador e terminam no polo de cada lado são chamados de meridianos.

Os círculos paralelos ao equador, que dividem o meridiano em seus graus, são chamados de paralelos.

Portanto, há tantos meridianos ou semicírculos quantos graus marcados no equador, ou seja, trezentos e sessenta.

\begin{tabular}{|c|c|c|c|c|}
\hline Qevista Dialeatus & Ano 10 & n. 23 & Maio - Agosto 2021 & p. $419-432$ \\
\hline
\end{tabular}


E existem tantos paralelos ou círculos inteiros, paralelos ao equador quantos graus marcados em um meridiano, ou seja, cento e oitenta, ou, contando a partir do equador, noventa de cada lado até o polo.

Os graus ou paralelos assim marcados no meridiano, contando do equador ao polo, medem a latitude. E os graus ou semicírculos marcados ao redor do equador pelos meridianos medem a longitude. A latitude tem sua medida fixa porque é contada a partir do equador.

Mas para encontrar a longitude, você precisa convencionar um meridiano, a partir do qual se começa a contá-la.

Este primeiro meridiano convencionado é o que passa pela Ilha de Ferro, uma das Canárias; é a partir desse meridiano principal que os graus de longitude são contados, contornando de oeste para leste ${ }^{4}$.

Quando sabemos a latitude e longitude de um lugar qualquer, podemos marcá-lo com muita exatidão no globo, porque ele estará no ponto de intersecção dos dois círculos.

A latitude é encontrada tomando a altura do polo ou do sol. Encontramos a longitude pela proporção de horas; mas esta operação tem sua dificuldade.

A altura do polo de um lugar qualquer é o arco do meridiano compreendido entre o horizonte daquele lugar e o polo.

A altura do sol é o arco do meridiano compreendido entre o horizonte de um local qualquer e o equador, que é medido pelo sol nos equinócios. No entanto, a altura do polo, igual à latitude, e a altura do sol sendo sempre o complemento uma da outra em noventa graus, podem sempre ser encontradas lado a lado.

Da mesma forma, nas luas cheias, a terra normalmente não é tão diretamente oposta entre o sol e a lua, que intercepta os raios do sol e os impede de atingir a lua; mas quando isso acontece, ocorre um eclipse lunar. Quando o eclipse, seja da lua ou do sol, é tal que os centros das três estrelas estão exatamente na mesma linha, o que é raro, então o eclipse é central.

Decorre do que acabamos de dizer que nunca há um eclipse solar que não ocorra em luas novas, e que nunca há um eclipse lunar que não se dê em luas cheias.

Uma vez que nenhum eclipse ocorre a menos que as estrelas que o fazem se encontrem, não apenas no Zodíaco, mas precisamente no círculo que passa pelo meio do Zodíaco, é por isso que este círculo é chamado de eclíptica.

\footnotetext{
${ }^{4}$ Lembramos que o Meridiano de Greenwich só foi convencionado no fim do século XIX.

\begin{tabular}{|c|c|c|c|c|}
\hline Q $R$ ovista Dialectus & Ano 10 & n. 23 & Maio - Agosto 2021 & p. 419-432 \\
\hline
\end{tabular}
}


Como o curso de cada astro é conhecido e medido com exatidão, sabemos com antecedência em que momento e em que pontos elas se encontrarão na eclíptica, e é por isso que podemos prever com certeza o momento em que ocorrerão os eclipses.

\section{Capítulo dez $z^{5}$}

Depois de ter falado dos círculos fictícios que a explicação da marcha do Sol nos fez imaginar, digamos uma palavra das divisões astronómicas da Terra assinaladas por esses mesmos círculos.

O globo terrestre é dividido em cinco faixas ou cintas chamadas zonas, das quais a do meio, a que fica sob a rota anual do sol, é chamada de tórrida ou ardente por causa dessa zona. Essa zona contém o espaço que está em cada lado do equador até o trópico. Ora, esse espaço [é] de vinte e três graus e meio, que é a quantidade do ângulo que a eclíptica forma no equador. Vinte e três graus e meio de cada lado juntos perfazem quarenta e sete graus para a largura total da zona tórrida entre os dois trópicos.

Tomando a mesma largura de vinte e três graus e meio a partir de cada polo no meridiano e desenhando a esta distância um círculo ao redor do polo; esse círculo é chamado de círculo polar, e a calota de vinte e três graus e meio que ele envolve é chamada de zona fria ou glacial, devido à sua extrema distância do sol. Como existem dois polos, também existem duas zonas glaciais, cada uma delas com o nome do polo que está no centro.

Desde o círculo polar de cada lado até o trópico, permanece uma distância de quarenta e três graus, que forma em ambos os lados duas outras zonas chamadas temperadas, por serem intermediárias entre a zona glacial e a zona tórrida.

O espaço total dessas cinco zonas é exatamente o da terra inteira. Porque contando do equador, em direção a um dos dois polos, temos primeiramente a metade da zona tórrida perfazendo vinte e três graus e meio; em seguida, uma zona temperada da qual os quarenta e três graus somados aos vinte e três e meio acima, perfazem sessenta e seis graus e meio, e ainda outros vinte e três graus e meio do círculo polar ao polo formam ao todo noventa graus, que são de fato a distância total do equador ao polo, e do mesmo modo do outro lado do equador até o polo oposto, perfazendo tudo os noventa graus que dividem o meridiano e toda a terra de um polo ao outro.

\footnotetext{
${ }^{5}$ Aqui a numeração dos capítulos é rompida por Rousseau. 
Antes de deixar a inspeção geral do globo terrestre, falaremos agora em um resumo de suas divisões reais por terra, mares, montanhas e rios.

Dissemos anteriormente que a Terra era dividida em dois meios-globos ou hemisférios. Um que é aquele no qual vivemos compreende o que é chamado de velho mundo, porque é conhecido há muito tempo; o outro compreende o novo mundo, descoberto há apenas três séculos.

Cada um dos dois hemisférios é composto de terras e de mares; mas essa composição é tal que o espaço dos mares é imenso e muito maior do que o da terra. O continente ou a terra de cada hemisfério é como uma grande ilha no meio desses vastos mares. A extensão total de terra que constitui o mundo está dividida em quatro partes principais, das quais o nosso continente inclui três; ou seja, a Europa, a Ásia e a África. O hemisfério ou continente oposto contém apenas uma, a saber: a América; mas ela sozinha é quase tão grande quanto os outros três conjuntos.

Das três partes que constituem o nosso mundo, a Europa e a África estão localizadas no Oeste ou no Ocidente, a Ásia no Leste ou Oriente, a África no Sul. As divisões dessas três partes são feitas por mares ou rios de acordo com sua posição. Quanto à América, sua figura e sua vasta extensão a tornam subdividida em duas partes. Uma, meridional, e a outra setentrional.

O grande mar, onde nadam as quatro partes do mundo, por assim dizer, é chamado de oceano; sua parte que fica entre a Europa e a América em nosso Ocidente é chamada de Mar do Norte; e sua parte que fica entre a Ásia e a América no Oriente, é chamada de Mar do Sul 6 . Existe um mar especial que separa a Europa da África e que só se comunica com o oceano através de um canal bastante estreito chamado Estreito de Gibraltar. Este mar é denominado Mediterrâneo; ele se comunica com o Oriente com um outro mar menor chamado Mar Negro ou Pont-Euxin; e novamente ao Oriente daquele, está outro pequeno mar na Ásia, que não tem comunicação com nenhum outro, ele é chamado de Mar Cáspio. Existem passagens marítimas para dar a volta ao mundo pela parte meridional. Mas ainda não se sabe se há também passagens para embarcações pela parte setentrional, o gelo impede a navegação. Há recompensas prometidas para aqueles que descobrirem esta passagem, e houve tentativas feitas por vários navegadores, mas até agora sem sucesso.

Há outro mar no norte da Europa chamado de Mar Báltico, que conecta o ocidente com o oceano por meio de um estreito chamado de Sund. Este mar está dividido em dois golfos

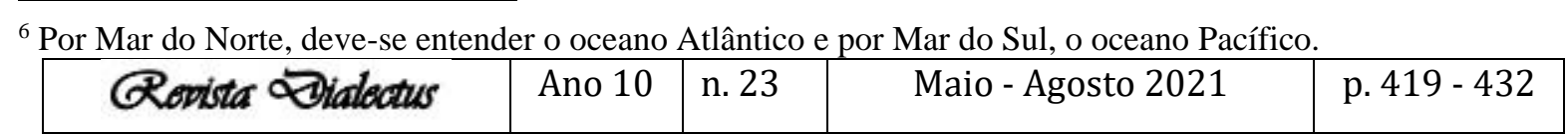


principais, um ao oriente denominado Golfo da Finlândia e o outro ao norte denominado Golfo de Bótnia. Entre a África e a Ásia existe outro mar chamado Mar Vermelho, que também se comunica com o oceano por meio de um estreito. No que diz respeito à América, apenas um mar pode ser distinguido por um nome particular, que separa quase inteiramente a parte setentrional da parte meridional e este mar é denominado Golfo do México.

Ao redor do continente estão espalhadas várias ilhas, algumas das quais formam países imensos. Tal como a ilha de Madagascar, ao oriente da África; a ilha do Japão ao oriente da Ásia; as Ilhas Britânicas, duas em número, nomeadamente a Grã-Bretanha, que inclui a Inglaterra e a Escócia; e a Irlanda, que é uma ilha e um reino particular. Ao norte das Ilhas Britânicas ainda existe uma grande ilha chamada Islândia. A América também apresenta em seu Ocidente um grande número de ilhas: entre outras, as Antilhas das quais Cuba, Jamaica e São Domingos são as mais importantes. O Mediterrâneo também inclui várias ilhas, das quais a Sicília é a maior; depois, as ilhas da Sardenha, Córsega, etc.

Os principais rios da Europa são o Tejo na Espanha; na França, o Ródano que recebe o Saône em Lyon e deságua no Mediterrâneo, o Garonne e o Loire que deságuam no oceano, bem como o Sena que passa pela capital. O Reno separa a França da Alemanha e deságua no oceano na Holanda. O Danúbio depois de passar pela Alemanha e a Hungria deságua no Mar Negro. O maior rio da Itália é o Pó; e o mais famoso é o Tibre. O mais famoso da África é o Nilo que atravessa e enriquece o Egito. Da multidão de rios que correm na Ásia, falarei apenas do Ganges, que corre para o sul, no mar da Índia, e do Don ou Tánais, que também deságua no mar Negro e se constitui em uma das separações entre a Ásia e a Europa.

Os principais rios da América em sua parte setentrional são o Mississippi, que deságua no Golfo do México, e o Rio São Lourenço, que atravessa o Quebec e deságua no Mar do Norte.

Desta infinidade de montanhas que dividem e se diferenciam nas várias regiões da terra, as maiores e mais conhecidas são: os Pirenéus que separam a Espanha da França; os Alpes que separam a França da Itália; os Apeninos que percorrem toda a Itália. Na África as cadeias do Monte Atlas, na Ásia o Monte Touro e na América as Cordilheiras.

Agora, para dizer algumas palavras sobre a situação de diferentes povos e divisões nacionais; começaremos pelo Ocidente da Europa, onde encontramos ao Sul, puxando para o oriente, primeiramente Portugal; depois a Espanha; depois a França; a seguir, a Itália, que se projeta para o Mediterrâneo na forma de uma bota que tem a Sicília na ponta do pé; e finalmente a Grécia, uma pequena região tão famosa na história antiga, e Constantinopla que termina no Oriente em direção à Ásia.

\begin{tabular}{|l|l|l|l|l|}
\hline Q Rovista Dialectus & Ano 10 & n. 23 & Maio - Agosto 2021 & p. $419-432$ \\
\hline
\end{tabular}


Então, começando novamente do ocidente, mais ao norte, encontramos a Holanda, a Alemanha, a Hungria e a Polônia, indo em direção ao oriente. No extremo Norte, partindo do ocidente para o oriente, encontramos a Escandinávia que circunda o Mar Báltico e é formada pelos reinos da Dinamarca e da Suécia. Depois, a Rússia, imenso império, do qual Petersburgo na Europa é a capital; mas que se estende na Ásia até as fronteiras da Tartária e da China.

\section{Capítulo onze}

Sobre esses elementos de cosmografia, embora informes e grosseiros, podemos traçar ideias da economia que reina na construção e na disposição de nosso globo. Vemos com que arte sublime, digna de seu divino criador, essa enorme [massa] se acha distribuída e iluminada de tal forma que todos os seres vivos que a cobrem possam viver e subsistir.

A chamada zona quente é temperada por nuvens e vapores contínuos que, nos locais por onde passa o sol, derramam longas chuvas para moderar o calor. As zonas glaciais, onde os raios lânguidos do sol parecem mal chegar, são aquecidas no verão pela extrema duração dos dias; de modo que nos países hiperbóreos, onde nada parece provável de crescer, os grãos são semeados, crescem, amadurecem e são colhidos no espaço de seis semanas, enquanto isso leva muito mais do que o dobro em nossos climas muito mais quentes. As longas e terríveis noites de inverno são encurtadas ali pelos longos crepúsculos, pois o sol se pondo muito mais obliquamente do que para nós não desce tão rápido no horizonte. Além disso, durante essas longas noites de inverno, essas regiões sombrias são quase continuamente iluminadas pelas auroras boreais e outros fenômenos luminosos que temperam o horror da escuridão e permitem aos habitantes discernir objetos.

Essas grandes cadeias de montanhas que parecem pesos desnecessariamente na terra são as nascentes e reservatórios dos rios e das fontes que vêm nos dar água. Além disso, as várias direções dessas montanhas dão origem a correntes de ar e ventos quase contínuos, cuja massa de ar é renovada e purificada. Esses imensos mares cujo sal os assegura da corrupção e cujo seio contém multidões de peixes para nosso uso, longe de cortar a comunicação entre as várias regiões do mundo, facilitam-na pela navegação. É por meio dela que o europeu, o americano, o africano, o asiático, que a Providência fez nascer tão distantes um do outro, se encontram continuamente reunidos e se enriquecem mutuamente pelas produções dos países que habitam. 
Os ventos periódicos e alísios, que os marinheiros chamam de monções, voltando constantemente nas mesmas estações, facilitam as longas viagens dos navios e fornecem aos navegadores os meios para atingi-los e deles tirar proveito.

Enfim, tudo, contanto que se lance um olhar reflexivo sobre os grandes e magníficos objetos com que a terra está coberta e adornada, digo tudo, nos mostra o que é poderoso e benéfico, que preparou esta terra para nossa morada, e que o homem estúpido e ingrato se atreve a ignorar.

Se reinasse na vida humana uma ordem como a que reina na natureza, com que visão comovente e bela não atingiria a face da terra? Mas os homens infelizes e bárbaros têm prazer em desfigurá-la com seus crimes e maldades; eles têm seu terrível prazer em atormentar uns aos outros. Traidores e enganadores até em suas aparentes carícias, confundem amigos e inimigos na mesma malícia, e fazem do espetáculo celestial deste mundo a verdadeira imagem do inferno.

\section{Referências}

ROUSSEAU, J.-J. Discurso sobre a origem e os fundamentos da desigualdade entre os homens. Tradução de Lourdes Santos Machado. São Paulo/SP: Abril S. A. Cultural e Industrial, 1973d. Introdução e notas de Paul Arbousse-Bastide e Lourival Gomes Machado.

ROUSSEAU, J.-J. Autobiographical, scientific, religious, moral, and literary writings. Lebanon/EUA: University Press of New England, v. 12, 2007.

ROUSSEAU, J.-J. Euvres complètes de Jean-Jacques Rousseau. Édition thématique du Tricentenaire. Tome X. Géneve: Slatkine, 2012.

ROUSSEAU, J.-J. O novo labirinto. Dialectus, Fortaleza/CE, n. 17, p. 293-300, Agosto 2020. Disponivel em: <http://www.periodicos.ufc.br/dialectus/article/view/60622>. Acesso em: 12 abril 2021.

\begin{tabular}{|l|l|l|l|l|}
\hline Qovista Dialeatus & Ano 10 & n. 23 & Maio - Agosto 2021 & p.419-432 \\
\hline
\end{tabular}

